Quaestio facti. Revista Internacional sobre Razonamiento Probatorio Quaestio facti. International Journal on Evidential Legal Reasoning Vol. 1 | 2020 pp. 177-198 Madrid, 2020

DOI: $10.33115 /$ udg_bib/qf.i0.22369 Marcial Pons Ediciones Jurídicas y Sociales

(C) Juan Pablo Aristegui Spikin ISSN: 2604-6202

Recibido: 31/04/2019 | Aceptado: 18/11/2019

\title{
LA PRUEBA ILÍCITA ANTE LA BIFURCACIÓN DEL TRIBUNAL PENAL
}

\author{
Juan Pablo Aristegui Spikin ${ }^{1}$
}

A Manuel Miranda Estrampes, in memoriam. Law shews itself in a mask. Jeremy Bentham ${ }^{2}$

RESUMEN: El artículo propone aproximarse a la prueba ilícita atendiendo al diseño institucional del sistema de justicia penal, a fin de mostrar problemas que de otra manera son ignorados. Utilizando las herramientas analíticas desarrolladas por la teoría racional de la prueba, se examinan las implicaciones de la bifurcación del tribunal penal en un tribunal de control de admisibilidad de las pruebas y un tribunal de juicio. Se emplea el proceso penal chileno como caso de estudio y se revisa críticamente el trasplante de excepciones a la regla de exclusión de prueba ilícita y la prohibición de valoración de prueba ilícita.

PALABRAS CLAVE: prueba ilícita, regla de exclusión, diseño institucional, admisibilidad, valoración

\section{ILLEGALLY OBTAINED EVIDENCE AND THE BIFURCATED CRIMINAL COURT}

1 Universidad Adolfo Ibáńez, Chile (juan.aristeguispikin@uai.cl). Agradezco a Manuel Miranda, Diego Dei Vecchi, Jordi Ferrer y Carmen Vázquez por sus valiosos comentarios a la versión original, presentada como trabajo final del programa de Master en Razonamiento Probatorio de la Universitat de Girona y la Università degli Studi di Genova.

2 Citado en Hart, 1982: 23. 
ABSTRACT: The paper argues for an approach to the topic of illegally obtained evidence that focuses on the institutional design of the criminal justice system, in order to highlight some issues that otherwise remain ignored. Using the analytical tools developed by the rationalist theory of evidence law, the paper examines the implications of a criminal court divided into two tribunals, both professionals, one in charge of the admission of evidence and the other functioning as trial court. By using the Chilean criminal procedure as a case study, the paper criticizes the transplant of exceptions to the exclusionary rule, and the prohibition of assessment of illegally obtained evidence.

KEYWORDS: illegally obtained evidence, exclusionary rule, institutional design, admission of evidence, assessment of evidence

SUMARIO: 1 . Introducción.-2. La prueba ilícita y la configuración del sistema acusatorio en Chile. 2.1. Principio acusatorio y regla de exclusión. 2.2. La regla de exclusión de prueba ilícita en el derecho procesal penal chileno.-3. La primera vía: admisión de la prueba ilícita. 3.1. El trasplante de las excepciones a la regla de exclusión. 3.2. Incompatibilidad del deterrence con el proceso penal chileno. - 4. La segunda vía: valoración de la prueba ilícita. 4.1. La "valoración negativa" de la prueba ilícita. 4.2. Los límites de la motivación. 4.3. El recurso de nulidad y la valoración de la prueba ilícita.-5. Cierre.-6. Bibliografía.

\section{INTRODUCCIÓN}

La discusión en torno a la prueba ilícita, tal y como suele desenvolverse en el contexto europeo continental y latinoamericano, ha tomado distancia respecto de las cuestiones de diseńo institucional del proceso penal, concentrándose en otros aspectos. Con ello, algunos problemas relevantes permanecen oscurecidos e incluso son agudizados por determinadas prácticas forenses. El presente artículo tiene por objeto poner de relieve algunas implicaciones en materia de admisión y valoración de la prueba ilícita, de la «bifurcación» (la expresión es de Mirjan DAMAšKa, 1997) del órgano jurisdiccional penal en un tribunal de control de admisibilidad de las pruebas $\mathrm{y}$ un tribunal de enjuiciamiento.

Con tal finalidad, el artículo se vale de las herramientas analíticas avanzadas por la contemporánea teoría racional de la prueba. Así, a modo de propósito colateral, se busca mostrar que dichos recursos conceptuales pueden ser eficazmente empleados para la crítica de diseños institucionales. Esto no debería resultar extraño a una teoría que encuentre en Jeremy Bentham a uno de sus precursores (Twining, 2006 y 1985), aunque solo asuma un compromiso "cuasi-benthamiano» (Ferrer, 2010). Siguiendo a H.L.A. Hart, el proyecto de Bentham se deja reconstruir como un programa de «desmitificación» del derecho (HaRT, 1982), dentro del cual la crítica de las instituciones ocupa un lugar central. El presente artículo busca dar un paso en ese sentido.

Un análisis de este tipo exige interiorizarse en las especificaciones de un determinado diseño institucional. Aquí se utiliza el proceso penal chileno como caso de estudio, si bien las observaciones que se formulan pueden ser -enfrentando los desafíos 
propios de todo examen comparativo- de provecho para la mejor comprensión de otros ordenamientos, ya sean de similar estructura o bien sirviendo de contraste. Son dos los atractivos del proceso penal chileno como caso de estudio: primero, como se reseña a continuación, el sistema de justicia penal vigente en este país ha asumido un compromiso con una estructura acentuadamente acusatoria; $y$, en segundo lugar y como consecuencia de lo anterior, conforme a dicho diseño se instituye la bifurcación del órgano jurisdiccional en dos tribunales profesionales. Este último aspecto permite focalizar el análisis en el objeto de interés trazado aquí, desligándose de otra dimensión de la bifurcación del tribunal penal tradicionalmente debatida en el contexto angloestadounidense: la supuesta dependencia del derecho probatorio respecto de la institución del jurado (Schauer, 2006).

La Corte Suprema de Chile ha hecho lugar a la admisión y valoración de prueba ilícita. A contrapelo de cierto discurso laudatorio sobre la reforma procesal penal chilena, del tenor de las disposiciones legales y de declaraciones de la propia Corte, ella acepta -sin decirlo y tal vez sin desearlo- que una condena penal se funde en prueba obtenida con infracción de garantías fundamentales. Dos han sido las vías abiertas para ello: en el nivel del control de la admisibilidad de la prueba, ha hecho aplicables las diversas excepciones a la regla de exclusión de prueba ilícita reconocidas por la jurisprudencia estadounidense. Y en el nivel de la valoración de la prueba, según ha instruido la Corte, cuando el tribunal de juicio llega a tomar conocimiento de un medio de prueba al que se ha accedido de manera ilícita (sin que se lo excluyera oportunamente en la audiencia preparatoria) debe valorarlo negativamente. Si bien esto puede ser entendido -como hace, en efecto, cierta dogmática bienintencionada- a modo de una postulada prohibición de valoración de prueba ilícita, aquí se pretende mostrar que esa posición soslaya las implicaciones del diseño institucional del proceso penal chileno. Se trata, en consecuencia, de una solución insatisfactoria ya que, paradojalmente, despoja al imputado del mecanismo previsto por la ley para impugnar la condena fundada en prueba ilícita.

\section{LA PRUEBA ILÍCITA Y LA CONFIGURACIÓN DEL SISTEMA ACUSATORIO EN CHILE}

Hoy en día es extendido el compromiso de los ordenamientos jurídicos con un -siguiendo la denominación usada por Manuel Miranda- principio de licitud de la prueba, conforme al cual «toda prueba debe obtenerse y practicarse con respeto a los derechos fundamentales» (Miranda, 2010: 132). Le acompaña la infaltable referencia a las palabras del Tribunal Supremo Federal alemán, elevadas a una especie de slogan de la disciplina del derecho procesal penal contemporáneo: la verdad no puede ser buscada "a cualquier precio» (BGHSt, 14 de junio de 1960, 14, 358, 365). De aquel principio se sigue que, respecto de la prueba tachada de ilícita, rige una prohibición de admisión y de valoración (MIRANDA, 2010:138) (o bien, en la fórmula desarrollada por la doctrina italiana, su inutilizzabilità (Miranda, 2013: 165-176)). No es relevante aquí referirse a todas las cuestiones interesantes que suscita la prueba 
ilícita en el derecho chileno o comparado. Simplemente, a fin de enmarcar la discusión de los siguientes apartados, en este se formulan algunas observaciones, más bien generales, acerca de la prueba ilícita y su relación con la específica configuración institucional del sistema de justicia penal chileno.

\subsection{Principio acusatorio y regla de exclusión}

El legislador chileno dio forma jurídica a la prueba ilícita mediante el establecimiento de una regla de exclusión, cuya operación se inserta en la propia estructura acusatoria del proceso penal. Si bien puede concederse que «entre acusatorio y regla de exclusión no existe una relación esencial, sino contingente» (Aguilera, 2008: 74), en el caso chileno el entrelazamiento entre ambos vino dado por la (por supuesto, contingente) historia de la superación del inquisitivo.

Hasta el año 2000 rigió en Chile un procedimiento penal de carácter fuertemente inquisitivo, heredado de la colonia española. Desenvolviéndose tempranamente el proceso de independencia nacional (1810-1818), el sistema de justicia penal chileno no tuvo siquiera la oportunidad de aprovechar la reforma ilustrada que atravesó el continente europeo durante el s. XIx y que alcanzó a Espańa en 1882. El proceso penal de la nueva república continuó rigiéndose, con adaptaciones, por el derecho monárquico, incluso ad portas del s. xx. El Código de Procedimiento Penal de 1906, que imperaría durante un siglo, actualizó dicha regulación sin pretensiones de introducir cambios al sistema, aun cuando su gestación tuvo a la vista las reformas europeas habidas para entonces. El compromiso institucional con el inquisitivo se radicalizó todavía más cuando, en 1927, los promotores fiscales fueron suprimidos. Así coincidieron -y se confundieron- en las manos de un mismo juez las funciones de investigar, acusar y juzgar.

La inercia legislativa cedió recién a fines del s. Xx, en parte gracias a la influencia del movimiento de reforma procesal penal que ya recorría Latinoamérica y a los esfuerzos de profundización de la democracia, que sobrevinieron a su recuperación tras desmoronarse las dictaduras. Pero no debe perderse de vista que el antiguo sistema había devenido incapaz de lidiar con el volumen de criminalidad que enfrentaba el país y fue la demanda local por mayor seguridad lo que propició que el proyecto de reforma fuera capaz de convocar el apoyo de distintos sectores políticos. Así, dos agendas políticas diferentes convergieron en el nuevo Código Procesal Penal del año 2000, planeándose su realización por medio de un procedimiento acusatorio y organizado en torno a la centralidad del juicio oral y público.

Esta configuración institucional refleja, en sus diversas capas, un contundente rechazo del inquisitivo y un reconocimiento del principio acusatorio que transformó la fisonomía del proceso penal chileno. Sin pretensión alguna de proporcionar una definición claire et distincte del acusatorio, aquí interesa destacar su principal manifestación institucional: provocar un doble desdoblamiento del Estado al interior del proceso penal. Primero, las funciones de acusar y juzgar fueron asignadas a órganos 
estructuralmente diferenciados, el ministerio público y el tribunal, respectivamente. Se trata de la dimensión esencial del acusatorio: quien acusa no juzga (ARMENTA, 2014: 29-93; 2012: 19-36; y 1998). Con ello se buscó asegurar la imparcialidad del tribunal al juzgar sobre el mérito de la acusación, imparcialidad que tanto se echaba de menos bajo el antiguo sistema. Junto con hacer posible un juzgamiento imparcial, este diseño sometió la hipótesis de la acusación a dos filtros: primero, la decisión del fiscal de acusar sobre la base del mérito de la acusación; y luego, la decisión del tribunal de condena o absolución sobre la base del mérito del juicio oral. Se trata de dos decisiones de diversa naturaleza, lo cual explica sus diferencias en cuanto al material sobre el cual se decide (la investigación en el primer caso, la prueba rendida en juicio en el segundo) y el estándar de prueba que debe sortearse ("fundamento serio" para acusar, "convicción más allá de toda duda razonable" para condenar). Pero se trata, además, de decisiones tomadas por dos órganos estatales diferenciados e independientes entre sí; y solo cuando tales decisiones coinciden, se dicta condena e impone una pena.

También se asignó al ministerio público la función de investigar. En vigor del Estado de derecho, la investigación penal no puede quedar enteramente entregada a la discreción del fiscal o la policía. La legitimidad de las medidas estatales coercitivas e intrusivas que son inherentes a la ejecución de esta función depende -para decirlo con las palabras de la Corte Suprema de los Estados Unidos en relación con la exigencia de autorización judicial previa- de «la interposición del juez entre el ciudadano y la policía» (por ejemplo, en McDonald $v$. United States, 335 U.S. 451, 455-456 (1948)). La urgencia de someter ciertas actuaciones estatales limitadoras de derechos constitucionalmente protegidos a control judicial enciende, sin embargo, otro foco de parcialidad del tribunal. A fin de ahogarlo, se articuló un segundo desdoblamiento del Estado, esta vez al interior de la propia organización judicial, el cual consistió en establecer dos tribunales con competencias diferenciadas: un tribunal (unipersonal y profesional) a cargo del control de la legalidad de la investigación y de la preparación del juicio, incluido el control sobre la admisibilidad de las pruebas (denominado juzgado de garantía) y un tribunal (colegiado y profesional) de enjuiciamiento (denominado tribunal de juicio oral en lo penal). De este modo, la bifurcación del tribunal penal se deja comprender a la luz del principio acusatorio y como garantía de la centralidad del juicio: el tribunal que decide sobre los hechos solo puede fundar su decisión en la prueba rendida en el juicio, ventilada "inmediatamente" en audiencia pública y expuesta a la confrontación de los litigantes. $\mathrm{O}$, dicho de otro modo, las actuaciones de la investigación carecen de valor probatorio, asegurándose así la «perplejidad» con que el tribunal de juicio debe aproximarse a la prueba, vale decir, la posición subjetiva "de quien todavía no sabe a qué atenerse, porque aún no conoce según las reglas» (ANDRÉs, 2015: 268, énfasis en el original).

Este modo de organización institucional de conformidad al principio acusatorio configura el contexto operativo de la regla de exclusión de prueba ilícita. Ahora, desde un punto de vista analítico, la conceptualización de una regla de exclusión supone situar su operación en el nivel de la admisibilidad de la prueba, esto es, siguiendo la 
distinción trazada por Jordi Ferrer, al producirse «la conformación del conjunto de

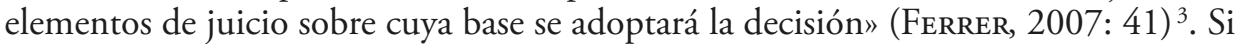
bien Ferrer advierte que admisibilidad, valoración y decisión conforme al estándar de la prueba corresponden a «tres momentos lógicamente distintos y sucesivos, aunque en los procesos de toma de decisiones reales pueden presentarse entrelazados» (ídem); en el caso del proceso penal chileno, el primero de esos momentos no solo puede ser analíticamente delimitado, sino que se encuentra estructuralmente diferenciado. Debido a esto, algo de la regla de exclusión se juega en la bifurcación del tribunal. Como ha mostrado Damaška, aunque suele fundamentarse la necesidad de contar con reglas de exclusión en la institución del jurado, atender a la división del tribunal puede arrojar una mejor $\mathrm{luz}^{4}$. Por supuesto, este autor viene comentando la separación entre los estadounidenses bench y jury, pero el argumento puede ser enteramente extendido a un sistema compuesto por jueces letrados profesionales en los dos extremos de la bifurcación (DAMAšKA, 1997: 27, n. 2), como es el caso chileno.

En lo restante de esta sección se caracteriza el modo de operación de una regla de exclusión y su vínculo con la estructura del tribunal, para mostrar luego cómo se inserta la regla de exclusión de prueba ilícita en ese esquema. Este panorama institucional proporciona el trasfondo de los apartados siguientes.

Ya se decía que el juicio sobre admisibilidad de la prueba da cuenta de los límites que se imponen al material probatorio que puede tener a la vista ( $¡ y$ al oído!) el tribunal al momento de juzgar. Este recorte de la realidad determina la especificidad de la prueba jurídica ${ }^{5}$ : el material de la decisión se agota en la prueba aportada y admitida al proceso. Esta peculiaridad jurídica se ve confirmada en tanto la composición de aquel conjunto de elementos de juicio resulta de la operación sucesiva de dos filtros de diversa naturaleza: primero, un criterio epistémico general, un principio de relevancia que «prescribe la admisión de toda prueba que aporte información relevante sobre los hechos que se juzgan» (FerRer, 2007: 42) ${ }^{6}$. De acuerdo con Ferrer, la vigencia de este principio se encontraría doblemente justificada: epistemológicamente, por cuanto "garantiza la mayor probabilidad de que los enunciados que se declaren probados coincidan con la verdad»; y jurídicamente, por cuanto condiciona el ade-

3 Cabe formular aquí una prevención: de acuerdo con Ferrer, este momento de la actividad probatoria no se agota en el examen de admisibilidad de los medios de prueba, sino que se extiende sobre fases posteriores del procedimiento, comprendiendo la rendición de la prueba en juicio. Esa dimensión resulta ensombrecida aquí, con la finalidad de vincular esquemáticamente la distinción de Ferrer con la bifurcación del tribunal y así ilustrar de manera más nítida el argumento. Mayor lealtad a la distinción de Ferrer exhibe Cortés-Monroy (2018).

4 Dice DAMAšKa, 1997: 26-27: «[E]n sí mismo, el factor del jurado no requiere de un derecho probatorio técnico. [...] El espacio para un derecho probatorio de carácter técnico comienza a abrirse solo cuando el tribunal de juicio se separa en dos partes. [...L] a creciente bifurcación del tribunal de juicio trae consigo un medioambiente institucional que favorece la aplicación efectiva de reglas que ocultan información probatoria al juzgador de los hechos».

5 Así, Ferrer, 2007: 41-42; y TARUffo, 2011: 327-357.

6 Sobre este criterio epistémico de relevancia, véase TARUfFo, 2011: 364-378; 2010: 161-176; 2008, 37-42; y FERRER, 2007: 68-76. 
cuado ejercicio del derecho a la prueba (ibidem: 78). Se lo puede caracterizar como un principio de inclusión de pruebas, toda vez que tiene prioridad lógica sobre el segundo filtro ${ }^{7}$ y prescribe «que toda prueba relevante sea por ello mismo admisible» (TARUfFo, 2011:368). Relevancia, aquí, es «equivalente al valor probatorio potencial de una proposición fáctica [...] medido en grados de probabilidad de que sea verdadera otra proposición fáctica que se infiere de la primera» (Muffato, 2014: 65). De este modo, un elemento de juicio «permite fundar en él (por sí solo o conjuntamente con otros elementos) una conclusión sobre la verdad del enunciado fáctico a probar» (FERRER, 2007: 71). Un criterio de este tipo, puramente epistémico, no basta para distinguir la prueba jurídica de otras formas de prueba. Hace falta que operen los criterios propiamente jurídicos de admisibilidad, los cuales adoptan la forma de reglas de exclusión, esto es, reglas que cumplen la función negativa de ordenar la exclusión de información que ha superado el umbral de la relevancia. Se trata, por consiguiente, de información que en términos estrictamente epistemológicos debería ser incluida. La decisión judicial sobre los hechos solo puede basarse, empero, en aquellos elementos de juicio incluidos por ser relevantes y no excluidos en razón de considerárselos jurídicamente admisibles.

La exclusión de prueba relevante eriza a epistemólogos y (algunos) juristas, e incluso llevó a Bentham a proclamar, muy en su espíritu abolicionista, palabras que hoy son tantas veces citadas en la literatura pertinente: «to exclude evidence is to exclude justice». En vista de la tensión entre el principio epistémico de inclusión y las reglas (jurídicas) de exclusión (que lo «excepcionan» (FERRER, 2007: 70)), estas últimas demandan una justificación robusta. Después de todo, la operación de una regla de exclusión importa un sacrificio epistemológico que puede disminuir las probabilidades de que la decisión judicial consiga dar por probados enunciados fácticos coincidentes con la verdad de los hechos.

La peculiaridad de la prueba jurídica reside, entonces, en la concesión epistemológica implicada en las reglas de exclusión y que puede fundamentarse por referencia a finalidades de dos diversas naturalezas: hay reglas de exclusión que, obedeciendo a consideraciones propiamente epistemológicas, ordenan la marginación de información que no obstante ser relevante, es de escaso valor probatorio o conlleva cierto riesgo de ser sobrevalorada por el juzgador de los hechos. Por ello se las puede calificar como reglas de exclusión intrínsecas al razonamiento probatorio (así, DAMAšKA, 1997: 14; y FERRER, 2007: 44 y 85). Y también las hay que obedecen a valores distintos de la averiguación de la verdad y que el ordenamiento jurídico estima bastantes como para justificar la exclusión de información relevante, y asumir el costo que ello implica en cuanto a la corrección de la decisión y la realización de otras finali-

Así, TARUFFo, 2011: 364: «Entre estos dos criterios [el de la relevancia de la prueba y el de su admisibilidad] hay un orden lógico según el cual la prioridad corresponde al de la relevancia: así, si una prueba es irrelevante no tiene sentido preguntarse si es o no jurídicamente admisible, ya que su adquisición sería en todo caso inútil: en consecuencia, el criterio de admisibilidad opera únicamente en el sentido de excluir del proceso pruebas que serían relevantes para la determinación de los hechos». 
dades jurídicas que dependen de esta última ${ }^{8}$. Se las puede calificar como reglas de exclusión extrínsecas al razonamiento probatorio (así, DAMAŠKa, 1997: 12; y Ferrer, 2007: 43 y 85). Las reglas de este último tipo producen, aunque de manera colateral, un efecto "contra-epistémico".

La riqueza de esta distinción es amplia y tal vez desatendida en su variedad. Aquí se la invoca con dos propósitos. Primero, el carácter extrínseco de la regla de exclusión de prueba ilícita ya anuncia las tensiones que le rodean. Y luego, como se espera mostrar, esta distinción permite visibilizar que estas dos clases de reglas de exclusión, en razón de sus respectivos fundamentos, se vinculan de manera diferente con la valoración de la prueba y la motivación de la decisión judicial sobre los hechos. Antes, sin embargo, corresponde referirse brevemente a la regla de exclusión de la prueba ilícita y su consagración en el ordenamiento jurídico-procesal penal chileno.

\subsection{La regla de exclusión de prueba ilícita en el derecho procesal penal chileno}

La sección previa pretende haber mostrado que, en el proceso penal chileno, la diferenciación analítica del "primer momento" de la actividad probatoria tiene un correlato institucional, diseñado de modo de resguardar la centralidad del juicio oral. Un tribunal bifurcado hace posible que el examen de admisibilidad de la prueba tenga lugar en una fase previa al juicio y ante un juez diferente, evitándose con ello que el tribunal de juicio llegue a tener contacto con la prueba a ser excluida y comprometa así su imparcialidad. Esta estructura permite que las reglas de exclusión cumplan su cometido. En esta sección se da cuenta de la operación de la regla de exclusión de prueba ilícita en particular.

El inquisitivo en Chile, como en otros ordenamientos, propugnó la eficacia de la prueba ilícita para sustentar una condena penal. De ahí que el legislador de la reforma procesal penal resolviera hacerse cargo del problema de la prueba ilícita y, de manera consistente con la estructura del procedimiento que instituía, diera a su solución la forma jurídica de una regla de exclusión. El específico modo de consagración normativa de una regla de este tipo es variado en el derecho comparado: es común que sea fruto del desarrollo (¡creación?) por un tribunal supremo o constitucional por medio de su jurisprudencia de control de la conformidad constitucional de las actuaciones de la persecución o el juzgamiento penal ${ }^{9}$. Común es también que esa jurisprudencia

8 El sacrificio epistémico producido por la exclusión de prueba puede redundar en frustrar no solo la finalidad de reducir errores, sino también la de averiguación de la verdad en tanto objetivo "estructuralmente necesario para que funcione el propio derecho como mecanismo de motivación de la conducta» (Ferrer, 2007: 82). De acuerdo con Ferrer, esto fundamenta que la averiguación de la verdad tenga prioridad sobre otros valores que pueden ser promovidos por medio del derecho probatorio.

9 Para el caso estadounidense, véase Allen et al., 2011: 340-352; Armenta, 20 i I: 29-34; Correa R., 2018a: 26-29; Hernández, 2005: 10-15; Kamisar, 2006; y Miranda, 2010: 134-135. Para el caso italiano, véase Armenta, 2011: 42-45; y Miranda, 2010: 135; y 2003: 53. Para el caso español, véase Aguilera, 2008: 83-90; y Miranda, 2010: 136-137; y 2003: 53-55. 
sea luego sucedida por modificaciones legislativas acordes. El caso alemán sigue una cuerda separada, reconociendo las así denominadas prohibiciones probatorias ${ }^{10}$. En Chile, en cambio, el legislador creyó necesaria la formulación expresa de una regla de exclusión de prueba ilícita a través del inciso tercero del artículo 276 del Código Procesal Penal ${ }^{11}$, en parte para sacudir las prácticas del inquisitivo y en parte a causa de la inclinación de la tradición jurídica de ese país hacia un razonamiento formalista, que hacía improbable que la práctica forense desarrollara prontamente una regla de exclusión por vía de interpretación de las garantías constitucionales del imputado. Sí tuvo lugar, sin embargo, un entendimiento por la doctrina y la jurisprudencia chilenas de que los efectos de la exclusión no solo alcanzan al material probatorio directamente obtenido con vulneración de derechos fundamentales, sino también, como corolario lógico, a todo aquel material probatorio derivado de esa ilicitud de base. Se trata de lo que en la tradición estadounidense se conoce como doctrina de los frutos del árbol envenenado y en Europa continental, con mayor sobriedad, como efecto reflejo de la prueba ilícita.

Ahora bien, ya se decía que, en vista de su carácter extrínseco al razonamiento probatorio, se vuelve ineludible la tarea de justificar la regla de exclusión de prueba ilícita, identificando con precisión su finalidad. Esto, sin embargo, es objeto de una disputa de nunca acabar y no es esta la oportunidad propicia para zanjarla. No obstante, en lo que resta de esta sección se aborda la cuestión solo en la medida indispensable para el posterior desenvolvimiento del argumento.

Entre la doctrina y jurisprudencia comparadas suele distinguirse, en general, dos alternativas de justificación de la exclusión de la prueba ilícita ${ }^{12}$. La comprensión actualmente imperante en el derecho estadounidense es que la exclusionary rule está orientada a regular la actividad policial (to police the police), disuadiendo -precisamente mediante la exclusión de la prueba ilícita- a los funcionarios policiales de realizar actuaciones que, aunque encaminadas hacia la legítima finalidad de obtener material probatorio incriminatorio, transgreden los derechos individuales garantizados por la Constitución. Así, la exclusión de la prueba ilícita solo resulta justificada contingentemente, esto es, solo en la medida en que ella sea efectivamente idónea

10 Para el caso alemán, véase Correa R., 2018b: 146-153; Hernández, 2005: 27-38; y Roxin, 2000: $\$ 24 . D, 188-207$.

11 Prescribe el inciso tercero del artículo 276 del Código Procesal Penal: «Artículo 276. Exclusión de pruebas para el juicio oral. [... El juez de garantía] excluirá las pruebas que provinieren de actuaciones o diligencias que hubieren sido declaradas nulas y aquellas que hubieren sido obtenidas con inobservancia de garantías fundamentales.»

12 Véase, por ejemplo, Jackson y Summers, 20 I 2: I 53-i 58 . En rigor, la diversidad de justificaciones es todavía más amplia que la presentada aquí. Una tercera alternativa asume que la regla de exclusión de prueba ilícita es intrinseca al razonamiento probatorio: la obtención de un determinado medio de prueba con infracción de derechos constitucionalmente protegidos es un indicio de que probablemente sea escasa la fiabilidad de dicho elemento de juicio. Se trata del tradicional problema de la confesión extraída bajo tortura, respecto de la cual ya la Constitutio Criminalis Carolina (1532) incluía una exigencia de corroboración. Aunque desde hace ya tiempo que una fundamentación de este tipo no suele encontrar adherentes, recientemente Jordi Nieva Fenoll ha salido en su defensa (Nieva, 2017). 
para producir el efecto disuasorio buscado y estén ausentes otros medios alternativos que, produciendo el mismo efecto, no impliquen tan alto costo epistémico.

En los sistemas jurídicos europeos continentales y latinoamericanos, en cambio, es tradicional sostener un fundamento distinto (aunque a ratos parece batirse en retirada). La exclusión de prueba ilícita sería consecuencia directa del «carácter preferente de los derechos fundamentales en el ordenamiento» (Miranda, 2003: 53). La legitimidad del ejercicio del ius puniendi estatal depende de que no se lo conciba como un poder desbocado, sino sometido a restricciones. El principal constreñimiento sobre la imposición judicial de una pena consiste en la exigencia de afirmación institucional de la culpabilidad del sujeto, lo cual supone que hayan sido probados los hechos que configuran el delito que se sanciona. Esto requiere de parte de los órganos de persecución penal que recopilen material probatorio suficiente, para lo cual necesitan practicar diligencias investigativas que afectan más o menos intensamente derechos constitucionalmente protegidos. Por lo tanto, estas medidas estatales intrusivas también se presentan necesitadas de legitimación y en caso de no garantizarse esta, difícilmente puede decirse que la imposición judicial de la pena constituyó un acto propio de un Estado de derecho. Se pone en jaque, así, la "integridad judicial" (y en rigor, no solo judicial, sino del aparato punitivo estatal en su conjunto). Una sofisticada defensa de esta fundamentación ha sido desarrollada también en el contexto anglosajón: de acuerdo con Antony Duff et al., la imposición de una pena «implica que el Estado, por medio del proceso penal, está en la posición moral de condenar al acusado» (Duff et al., 2007: 225, énfasis añadido). Según este tipo de justificaciones, habría un fundamento "ético" o "principista" para excluir la prueba ilícita. Así lo ha entendido la Corte Suprema chilena, que reiteradamente ha afirmado que «la negativa a admitir prueba ilícita tiene como fundamento la preservación de la integridad judicial» (por ejemplo, en sentencia de 20 de abril de 2017 , rol no. 39.475-16, considerando $11^{\circ}$ ). Esta pareciera ser también la posición del legislador, que ha incluido sendas reglas de exclusión de prueba ilícita en la regulación de la justicia de familia y de la justicia laboral, donde no tiene cabida la finalidad disuasoria sobre agentes estatales.

Ahora bien, quien defienda una justificación "moral” de la exclusión de prueba ilícita no objetará que ella pueda producir, además, un efecto disuasorio sobre la policía. Pero se tratará simplemente de un subproducto o, en el lenguaje de los economistas, una externalidad positiva. A la inversa, de fundarse la exclusión de prueba ilícita en el deterrence, no se estará brindando suficiente protección a la integridad judicial, puesto que esta justificación con demasiada facilidad se muestra disponible para hacer excepciones a la regla de exclusión. Un auténtico defensor del fundamento ético de la regla de exclusión de prueba ilícita no solo debe hacer declaraciones de principios, sino que debería rechazar tales excepciones para ponerse a recaudo del riesgo de comprometer su integridad. La Corte Suprema de Chile, sin embargo, ha resuelto distinto. 


\section{LA PRIMERA VÍA: ADMISIÓN DE LA PRUEBA ILÍCITA}

El propósito de este apartado es acotado: se busca mostrar que, a pesar de lo dicho hasta ahora, la Corte Suprema chilena ha abierto una vía para afirmar la admisión de prueba obtenida con infracción de garantías fundamentales. Se trata de las excepciones a la regla de exclusión. Sin que sea posible hacerse cargo de ellas aquí ${ }^{13}$, nada más se intenta mostrar cuán frágil es su justificación dentro del proceso penal chileno.

\subsection{El trasplante de las excepciones a la regla de exclusión}

El legislador chileno ha permanecido silente en cuanto a las posibles excepciones a la regla de exclusión de prueba ilícita. Este silencio, sin embargo, no ha representado obstáculo alguno para que la Sala Penal de la Corte Suprema las desarrolle motu proprio. La estrategia argumentativa empleada para ello no ha supuesto originalidad de parte de la Corte: se dice que las buenas ideas hay que copiarlas. Así, ha trasplantado las excepciones desde la jurisprudencia estadounidense, recibiéndose en el ordenamiento jurídico chileno tanto la excepción de buena fe del funcionario policial ${ }^{14}$, como las excepciones a la doctrina de los frutos del árbol envenenado (fuente independiente, vínculo atenuado y descubrimiento inevitable). Como se intenta mostrar enseguida, esta operación de importación se ha desarrollado a espaldas del contexto institucional en que la jurisprudencia estadounidense generó las mismas excepciones.

La expansión de la regla de exclusión en los Estados Unidos se produjo durante la segunda mitad del período de la Corte Warren (1953-1969) (KamIsAR, 2006), lapso en que dicho tribunal explotó su jurisdicción de certiorari y valiéndose de la doctrina de la incorporación, hizo aplicable a nivel estadual los estándares de persecución penal contenidos en la Bill of Rights, hasta entonces de sola aplicación federal. Pero el auge de los postergados derechos del imputado pronto dejó ver su contracara: las decisiones de la Corte Warren impusieron un costo demasiado alto sobre la persecución penal y aunque no han sido formalmente revocadas (overruled), sí han sido contrarrestadas legislativamente y no puede decirse que hayan logrado asegurar su propia estabilidad en el tiempo ${ }^{15}$. Tan pronto como llegó el tiempo de la sucesión del Chief Justice Earl Warren, la Corte Burger comenzó a restringir el alcance de la regla de exclusión y asentar su fundamento en su efecto disuasorio resultó especialmente

13 Véase Allen et al., 2011: 658-673 y 685-706; Correa R., 2018a; Hernández, 2005: 17-26 y 73-85; Miranda, 2010: 140-148; y 2003: 57-59 y 64-66.

14 Véase, con detalle, Correa R., 2018 a.

15 Lawrence Friedman, 1993: 302, reporta: «Esas dramáticas decisiones de la Corte Warren resultaron muy controversiales. Se les dio mucha publicidad y para los tribunales, a diferencia de Broadway, no toda publicidad es buena publicidad. La Corte fue criticada, en ocasiones de manera histérica, acusándosele de pervertir el sentido de la Constitución». Crítico de los logros de la Corte Warren, por pírricos, Stuntz, 2011: 216-243 («Es una de las extrańas ironías de la historia que Earl Warren [...] ayudó a acomodar la entrada de las duras políticas contra el crimen» (ibid.: 216). 
propicio. Fue el momento, entonces, de la expansión de las excepciones a la regla de exclusión: allí donde la supresión de la prueba obtenida era incapaz de producir un efecto disuasorio, la regla no debía operar.

Por supuesto, también los ordenamientos que suscriben el fundamento del resguardo de la integridad judicial deben enfrentar las tensiones provocadas por la exclusión de prueba, viéndose en la necesidad de encontrar alguna válvula de escape. Así, la Corte Suprema chilena ha hecho convivir, con asperezas, sus declaraciones sobre la justificación ética de la exclusión de prueba ilícita y las excepciones a la regla de exclusión ${ }^{16}$. Muchas veces, el trasplante se realiza de manera tosca, concediéndose a la respectiva excepción un alcance más amplio que el dado por la jurisprudencia estadounidense ${ }^{17}$; y en otras ocasiones, el proceder del máximo tribunal chileno es sencillamente incomprensible: combina las excepciones $(\mathrm{i} !)^{18}$.

Más allá de una falta de pudor intelectual, esta desarticulada recepción de las excepciones a la regla de exclusión pone de manifiesto el rol que ellas desempeñan. Permiten a la Corte, de un lado, declarar su compromiso con la protección de las garantías del imputado a través de la exclusión de la prueba ilícita; mientras que, de otro lado y a la vez, se permite eludir la carga impuesta por dicho compromiso. Y esta ambivalencia se expande a lo largo del sistema de justicia: no se trata simplemente de decisiones aisladas, sino de una jurisprudencia a ser observada por los jueces de garantía en la audiencia preparatoria a propósito del debate sobre exclusión de las pruebas. Esta es la primera vía abierta por la Corte para hacer lugar a condenas basadas en prueba ilícita, con ocasión de un punto crítico del diseño institucional del proceso penal chileno: el juicio sobre la admisibilidad de la prueba.

16 Por ejemplo, en su sentencia de 20 de abril de 2017, rol no. 39.475-16, tras recordar que en el ordenamiento jurídico chileno la exclusión de prueba ilícita se basa en la protección de la integridad judicial, la Corte pasa a citar cinco decisiones de la Corte Suprema de los Estados Unidos (Mapp v. Ohio, 367 U.S. 643 (1961); Wong Sun v. United States, 371 U.S. 471 (1963); Brown v. Illinois, 422 U.S. 590 (1975); Leon v. United States, 468 U.S. 897 (1984); y Utah v. Strieff, 579 U.S. _ (2016)), para acabar sustentando la aplicación de la excepción de vínculo atenuado.

17 Compárese, en relación con la excepción de descubrimiento inevitable, la decisión de la Corte Suprema de Estados Unidos en Nix v. Williams, 467 U.S. 431 (1984), y la decisión de la Corte Suprema de Chile, de 3 de noviembre de 2014, rol no. 14.781-15.

18 En su sentencia de 16 de septiembre de 2013, rol no. 4653-13, la Corte Suprema de Chile combina las excepciones de buena fe y descubrimiento inevitable con la finalidad de amparar el ingreso de funcionarios policiales a un domicilio particular sin orden judicial que lo autorizare: «[E]l fallo [recurrido] se hizo cargo de la supuesta infracción de garantías en la recolección de la prueba al sostener que "los funcionarios policiales que tomaron parte de la diligencia en comento dieron cumplimiento a las exigencias del texto del Código Procesal Penal al entender que recibieron legítima autorización para la entrada y registro de [parte de] quien apareció como encargado de dicha propiedad. [... B]ien pudo requerirse al tribunal de garantía competente, de haber sido necesario, la competente [sic] autorización judicial de entrada, registro e incautación [...], de manera que el hallazgo del arma aparecía como una cuestión inevitable, por lo que el supuesto vicio denunciado ninguna trascendencia ha podido tener en el resultado del juicio» (considerandos $7^{\circ}$ y $8^{\circ}$ ). 


\subsection{Incompatibilidad del deterrence con el proceso penal chileno}

En contra de la inconsistencia apuntada en la sección anterior, podría argumentarse que la jurisprudencia de la Corte evidencia, más que un trasplante torpe, una migración hacia el deterrence como fundamento de la exclusión de prueba ilícita. Después de todo, un movimiento en esa dirección puede apreciarse desde hace ya un tiempo en el derecho comparado. Esta sección tiene por finalidad mostrar que ese rumbo está vedado para la Corte en razón del diseño institucional del proceso penal chileno.

El favorecimiento del deterrence se explica por su plasticidad. Bajo esta concepción, la regla de exclusión debe ceder en todo caso en que se disponga de un medio alternativo capaz de producir el mismo efecto y que signifique un menor costo. En esta línea suele reivindicarse la posibilidad de imponer sanciones penales o disciplinarias a los funcionarios policiales, así como hacer valer su responsabilidad civil. Sin embargo, la literatura especializada tiende a quedarse en la mera enunciación de estos medios alternativos y no ofrece pruebas de su eficacia. Por ejemplo, si se mira la práctica de muchas agencias policiales estadounidenses de contratar pólizas de seguro para cubrir los riesgos de ser demandadas por mala praxis policial y condenadas al pago de millonarias indemnizaciones, se advertirá que las compañías aseguradoras regulan contractualmente (en función de la determinación de la cobertura del seguro) la conducta policial. Nótese que se trata del mismo fin atribuido a la regla de exclusión: to police the police. Sin embargo, el impacto de esta "regulación privada" es bastante menor precisamente tratándose de los casos rutinarios de obtención ilegal de material probatorio de cargo, puesto que estos implican riesgos que son catalogados como menores o insignificantes. No hay incentivos que motiven a las compañías aseguradoras a prestar atención a este tipo de hechos (RAPPAPORT, 2016).

Pero, además de no proporcionarse evidencia acerca de la eficacia de las medidas alternativas, se pasa completamente por alto el contexto institucional específico. Regular la conducta policial es una tarea primordial de todo Estado de derecho. Al hacerlo, se debe definir tanto los comportamientos que necesitan ser regulados, como los mecanismos de control adecuados: la regla de exclusión fracasa en ambos extremos. Naturalmente, no se hace cargo de todas las conductas policiales que deben ser reguladas, sino solo de aquellas orientadas a la recopilación de material probatorio. Y, por otro lado, no parece ser un medio eficaz de control del actuar policial. Algunos ordenamientos europeos continentales y latinoamericanos someten a la policía a la dirección del ministerio público (Roxin, 1993: 42). Al evaluarse la idoneidad de la regla de exclusión para regular la conducta policial, debe prestarse atención a la configuración de la relación entre la policía y el ministerio público, y especialmente a la distribución de la responsabilidad sobre la investigación.

En el caso del sistema de justicia penal chileno, por ejemplo, la investigación es dirigida de manera exclusiva por el ministerio público, no estando la policía autorizada para investigar de manera autónoma. Los funcionarios policiales, salvas excepciones, solamente pueden actuar por instrucción del fiscal, «ejecutan[do] sus tareas 
bajo la dirección y responsabilidad de los fiscales» (artículo 80 del Código Procesal Penal). En consecuencia, el pretendido efecto disuasorio se encuentra desterrado por definición legal. A lo más, podría operar de manera indirecta, mediado por el fiscal. Sin embargo, en los hechos, la audiencia preparatoria en que se debate la exclusión de prueba ilícita se sitúa más allá del horizonte operativo de las agencias de policía. Esto significa que el destino del material probatorio recopilado es, en realidad, irrelevante para los funcionarios policiales ${ }^{19}$. Esto parece suficientemente sintomático: dada la específica distribución del trabajo al interior del sistema de justicia penal chileno, se produce una compartimentalización de la responsabilidad que hace imposible que la regla de exclusión produzca el efecto que se le atribuye.

Las consideraciones anteriores bastan para descartar el deterrence como fundamento de la exclusión de la prueba ilícita en el ordenamiento jurídico chileno, dada la configuración institucional actual. Esta conclusión se basa, por cierto, en un argumento enteramente sensible a las formas específicas de organización de la persecución penal en un ordenamiento jurídico determinado, de modo que no puede ser generalizado. A pesar de ello, el argumento sí ofrece algo valioso para otros ordenamientos: muestra la conexión entre la regla de exclusión y el diseño institucional del proceso penal. La misma vinculación puede encontrarse, por ejemplo, en el derecho estadounidense: la Corte Warren se propuso hacer realidad la promesa de los Founding Fathers de que la Bill of Rights brindara protección a toda persona, especialmente a quienes más la necesitaban. Para ello, no sólo hizo de la carta de derechos un código de procedimiento penal de rango constitucional (FriendiY, 1965), sino que la llevó dentro de los cuartos de interrogatorio de las estaciones de policía. Ese fue el modo que encontró para alcanzar a un inmenso número de funcionarios policiales dispersos a lo ancho del país y adscritos a un espectro amplísimo de agencias públicas dependientes de un espectro igualmente amplísimo de autoridades locales, de condado, estaduales y federales. De eso se trató «el primer disparo de la revolución de la Corte Warren» (Kamisar, 2006): Mapp v. Ohio; de eso se trató la regla de exclusión de la prueba ilícita.

Por último, descartar el efecto disuasorio como fundamento de la exclusión de prueba ilícita no puede contar, sin más, como confirmación del resguardo de la integridad judicial como fundamento. La evaluación de esta justificación no es objeto del presente trabajo. Aquí solo interesa concluir que la Corte Suprema chilena ha tomado distancia respecto del diseño institucional instaurado por la reforma del ańo 2000, con tal de aceptar las excepciones a la regla de exclusión de prueba ilícita.

19 Así, por ejemplo, invocando la Ley de Transparencia de la Función Pública y de Acceso a la Información de la Administración del Estado, se consultó a Carabineros de Chile (una de las dos agencias nacionales de policía) cuántas detenciones fueron practicadas por sus funcionarios durante 2017 y que luego hayan sido judicialmente declaradas ilegales (solicitud No. AD009W0039900, de 18 de diciembre de 2017). La institución respondió indicando que ella no registra esa información y remitió la consulta al ministerio público. Carabineros de Chile no lleva la cuenta de las actuaciones de sus funcionarios que los tribunales estiman como afectaciones ilegales a la libertad de los ciudadanos. 


\section{LA SEGUNDA VÍA: VALORACIÓN DE LA PRUEBA ILÍCITA}

Aun cuando fuera admitida a juicio prueba tachada de ilícita, ella no es saneada por esa sola circunstancia formal. Si bien la dogmática procesal convive con incomodidad con la persistencia de la ilicitud y esgrime la carta de la cosa juzgada o a lo menos de la preclusión, los defensores de la integridad judicial replican, no obstante, que ella posee una dimensión de integración de acuerdo con la cual «las distintas partes del proceso penal no pueden ser aisladas unas de las otras. En particular, el juicio penal no puede reclamar que su integridad moral se encuentra aisladamente intacta, mientras que hayan ocurrido errores en una fase previa del proceso" (Duff et al., 2007: 226). Por eso el uso de la expresión "integridad judicial" es siempre impropio, por reduccionista: se trata de la integridad del sistema de justicia en su conjunto.

En el caso chileno, la posibilidad de impugnar la sentencia condenatoria basada en prueba no excluida en la etapa intermedia se encuentra expresamente prevista en la ley ${ }^{20}$. El mecanismo disponible para hacer efectiva esa impugnación es el recurso de nulidad, el cual procede -inter alia- frente a una infracción sustancial de las garantías fundamentales del imputado, que haya ocurrido en cualquier etapa del procedimiento o en el pronunciamiento de la sentencia. Se ha entendido que se incurre en esta causal cuando el tribunal de juicio valora prueba ilícita y hace uso de ella para fundamentar una sentencia condenatoria. Ello constituiría en sí mismo una vulneración del derecho del condenado al debido proceso.

Como ya se advierte, el mecanismo recién descrito presupone la conclusión del juicio y la dictación de la sentencia definitiva. Esta solución tiene que aparecer como insatisfactoria ante los ojos de quien sostenga que la prueba ilícita "conlleva su inutilizzabilità procesal, esto es, la prohibición de su admisión así como de su valoración por el tribunal sentenciador» (MiRANDA, 2010: 138). La cuestión ha sido debatida entre la doctrina chilena ${ }^{21}$, especialmente porque el legislador previó una regla de exclusión de la prueba ilícita y una oportunidad procesal precisa para que ella opere, sin que resulte claro si ello importa una probibición de valoración de la misma en el juicio oral. Aunque la cuestión no se encuentra zanjada, dado el compromiso comulgado con el resguardo de la integridad judicial, se ha impuesto tanto en la doctrina como en la jurisprudencia el entendimiento de que rige tal prohibición. Ella se traduciría, de acuerdo con la Corte, en un deber del tribunal de juicio de "valorar negativamente" la prueba ilícita. Este apartado pretende mostrar que, con esto, este tribunal nuevamente ha dado la espalda al diseño institucional del proceso penal chileno: el cumplimiento de dicho deber no resuelve el problema de contaminación del juicio del tribunal y, en cambio, torna inexpugnable su decisión. Así, la Corte ha conseguido abrir una segunda vía para las condenas fundadas en prueba obtenida con infracción de garantías fundamentales.

20 Así ha sido entendida la regla del inciso segundo del artículo 277 del Código Procesal Penal que reserva «la procedencia, en su caso, del recurso de nulidad en contra de la sentencia definitiva que se dictare en el juicio oral, conforme a las reglas generales».

21 Véase al respecto, Correa R. (2018b); Hernández (2005): 90; Horvitz y López (2002): 196-200. 


\subsection{La "valoración negativa" de la prueba ilícita}

No es claro qué quiere decir la Corte cuando utiliza la expresión “valoración negativa", pero pareciera tratarse de una fórmula de compromiso que tiene el objetivo de compatibilizar la prohibición de valoración de prueba ilícita, con el deber de fundamentación de la decisión sobre los hechos del caso. Así las cosas, el tribunal de juicio que se ve enfrentado a prueba que estima ilícita y que no fue debidamente cribada por el juez de garantía en la audiencia preparatoria, no podrá utilizarla para fundar su decisión y deberá, con carga a la motivación de la sentencia, dar razones de ello. Esto último permitiría «detectar a través de la motivación fáctica la eventual incidencia que una prueba ilícita haya podido tener en la valoración del resto de las pruebas de cargo practicadas» (Miranda, 2012: 310). La prueba acusada de ilícita, por lo tanto, no puede servir de base para inferencias probatorias conducentes a dar por probado un determinado hecho. Y si lo hiciera de modo clandestino, la fundamentación de la decisión obliga al tribunal a ponerlo en evidencia, haciendo posible el control de la sentencia a través del recurso de nulidad.

\subsection{Los límites de la motivación}

Deben ser reconocidos los esfuerzos argumentativos de parte de la doctrina -en general de impronta alemana-, así como de la propia Corte Suprema, por armonizar el principio de licitud de prueba con la regulación del procedimiento penal chileno. En efecto, desde un punto de vista dogmático, esta posición al menos proporciona una solución de lege lata que consigue sobreponerse a las dificultades que el crítico simplemente elude con su ingenio de lege ferenda. Pero, a veces, el remedio puede resultar peor que la enfermedad y entonces urge denunciarlo.

Los defensores de una prohibición de valoración de prueba ilícita se exceden en su optimismo respecto del control expost de la decisión sobre los hechos en virtud de la motivación de la sentencia. Así, por ejemplo, Manuel Miranda:

Es cierto que siempre es posible maquillar la motivación, pero, además de ser esta una patología contraria a la ética judicial y a la normativa constitucional y procesal, me atrevo a afirmar que estas operaciones de maquillaje encierran, en la totalidad de los casos, defectos y lagunas en la motivación que resultan plenamente apreciables y que vician de nulidad radical a la sentencia. La motivación en serio de las sentencias, entendida en clave de justificación, y su función profiláctica son un verdadero antídoto frente a la arbitrariedad judicial y a los riesgos derivados de una eventual contaminación de la prueba ilícita. (Miranda, 2012: 311 (énfasis en el original)).

En efecto, a nadie se le escapa que en tal situación ya habrá fracasado la exclusión de prueba, no pudiendo evitarse que el tribunal de juicio haya tomado conocimiento de la información proporcionada por el elemento de prueba prohibido. Pero, se argumenta, la motivación de la sentencia y la disponibilidad de algún medio para su impugnación lograrán paliar el efecto contaminante de la prueba ilícita. 
Puede ponerse en cuestión la eficacia de estos mecanismos, sin embargo, a la luz de la distinción entre reglas de exclusión intrínsecas y extrínsecas al razonamiento probatorio. Como se indicó, las primeras buscan «aumentar la exactitud de la averiguación de los hechos» (DAMAšKA, 1997: 14), excluyendo evidencias de escasa fuerza probatoria o que conllevan cierto riesgo de sobrevaloración o cierta capacidad generadora de prejuicios. En rigor, estas reglas podrían estimarse prescindibles en dos sentidos diversos: primero, en tanto criterios jurídicos de admisibilidad, miran a deficiencias que podrían ser evaluadas por el tribunal de juicio sin necesidad de entrar a conocer cabalmente la información que intentan excluir. No habría, por tanto, una estrecha intimidad entre este tipo de reglas y la bifurcación del tribunal. En segundo lugar, tales deficiencias podrían ser adecuadamente abordadas con ocasión de la valoración de la prueba. De ahí que sean estas reglas el principal objeto de la crítica abolicionista ${ }^{22}$. Por esta misma razón, la motivación de la decisión sobre los hechos aparece como un mecanismo que hace posible un adecuado control ex post de esa valoración.

Nada de eso puede decirse respecto de las reglas de exclusión extrínsecas, como es el caso de la regla de exclusión de prueba ilícita. Al carecer de justificación epistemológica, su sentido y eficacia dependen de evitar que en caso alguno llegue el tribunal de juicio a conocer la información que se pretende excluir. Por ello, no podría reservarse para el momento de la valoración de la prueba la decisión sobre la incorporación de esa información al acervo del tribunal sentenciador. Hay aquí un compromiso necesario con la bifurcación del tribunal. En caso de que el tribunal de juicio llegue a conocer la información que se buscaba excluir, no puede exigírsele que simplemente la ignore, pues «no parece probable que la mente humana sea capaz de procesar información de manera tan estrictamente compartimentalizada» (DAMAšKA, 1997: 48). Y en derecho, ultra posse nemo obligatur. El tribunal de juicio, sea de manera deliberada o -con mayor probabilidad- sin siquiera percatarse de ello, se verá en la necesidad de cubrir con sombras las auténticas razones de su decisión y racionalizar su justificación. Tratándose de la información que es objeto de las reglas de exclusión extrínsecas, el control ex post de la justificación de la decisión sobre los hechos se verá gravemente debilitado.

\subsection{El recurso de nulidad y la valoración de la prueba ilícita}

Con la reforma al sistema de justicia penal chileno se adoptó un nuevo régimen de recursos, coherente con la centralidad del juicio oral y público. La doctrina chilena suele interpretar este cambio echando mano a las categorías de ideal jerárquico e ideal de coordinación, introducidas por DAMAšKA (1986). El sistema de recursos es, efectivamente, sintomático del carácter de la organización judicial y de manera más

22 «[S]iendo reglas intrínsecas al razonamiento probatorio, no estarían fundadas en otros valores que puedan contraponerse al de la averiguación de la verdad. Las reglas probatorias de este tipo constituyen los casos más claros que Bentham y sus seguidores pretenden abolir» (Ferrer, 2007: 85). 
general, de la forma de organización del poder del Estado. Comentando la tardía aparición de la apelación dentro de la tradición del common law, el comparatista R.C. van Caenegem apuntó: «La introducción de la apelación es un evento político en la medida en que implica el sometimiento de los tribunales inferiores a la autoridad de los tribunales superiores, lo que es una cuestión de la política del poder» (CAENEGEM, 1993: 6). El así denominado efecto devolutivo, propio de la apelación, da cuenta de una organización judicial monárquica, en la que el poder de juzgar se concentra en el rey y es delegado a sus funcionarios subalternos: apelando, el recurrente solicita la devolución del poder de juzgar delegado. Bajo esta lógica, el control jerárquico es extenso y la revisión de la decisión escrutada abarca todos sus aspectos, de hecho y de derecho.

También esta dimensión del inquisitivo fue abandonada por la reforma procesal penal. Así, con el recurso de nulidad,

se ha desplazado el sistema de la doble instancia como recurso generalizado hacia la concepción del recurso como control de legitimidad del juzgamiento. [... E]l actual sistema de recursos tiene como rasgo que es muy limitado y supeditado a la ideal central de que el juicio oral es único, remitiéndose para ello a los principios de oralidad e inmediación. Su rasgo esencial es que la decisión se adopta en virtud de la prueba percibida directa e inmediatamente por los miembros del tribunal a través de sus propios sentidos [...] (ARAYA, 2018: 44-45).

Como se advierte, el principio acusatorio conlleva una restricción del ámbito de lo revisable vía recurso de nulidad. Fue esta limitación la que, en los tiempos de la reforma, puso en jaque su compatibilidad con el estándar internacional del derecho al recurso. Proyectada la discusión en perspectiva histórica, no puede dejarse pasar que el contemporáneo derecho internacional de los derechos humanos reclama un poder de revisión de la sentencia condenatoria propio del Estado del ancien régime.

Por otra parte, puede criticarse que este diseño adolece de cierta inclinación hacia lo que Perfecto Andrés Ibáñez ha denominado «mística de la inmediación» (ANDrés, 2015: 272-277; y 2003: 57-66). Eso explica que un connotado jurista chileno (j!) haya destacado que el juicio oral permite al tribunal «formarse convicción por la interactuación de todos sus sentidos» (TAVOLARI, 2005: 204) y en consecuencia, "la denominación de "juicio oral" es insuficiente, porque no representa cabalmente la característica de aprehender el juez las circunstancias del thema decidendum con todos sus sentidos y no meramente con el oído» (ibid.: 204, n. 143). Cabría referirse entonces a algo así como el juicio sensorial (y es de esperarse que sea solo pentasensorial...).

Esta combinación (restricción de lo revisable y deferencia hacia la inmediación) ha redundado en que el recurso de nulidad solo sirva limitadamente para el control de la decisión judicial sobre los hechos ${ }^{23}$. No puede ahondarse aquí en esta materia. Basta con destacar que, al ponerse el corazón de la reforma procesal penal en el derecho del imputado al juicio oral, ella sirve a dos señores a la vez: por un lado, el juicio mismo sería la mejor garantía de racionalidad de la decisión judicial; del otro

23 Véase Accatino, 2010; 2009; y 2006; y Araya, 2018. 
lado, escondería una concepción subjetivista de la valoración de la prueba. Como consecuencia de ello,

"lo visto y oído" por el juez en ese encuentro sublime con sus fuentes de información, a más de no ser [...] verbalizable y justificable, sería también de imposible fiscalización, por quien no hubiera participado, y en el mismo plano de proximidad, de la misma singular experiencia. (ANDrés, 2003: 58).

Es posible volver ahora sobre la cuestión de la "valoración negativa" de la prueba ilícita. Si el tribunal de juicio enfrentado a un elemento probatorio prohibido cumple con la tarea con que le ha cargado la Corte y lo valora "negativamente", los enunciados fácticos dados por probados en la sentencia aparecerán fundados en otros elementos de juicio. Esto puede controlarse en virtud de la satisfacción del deber de fundamentación de la sentencia: como señala Accatino, el control de la motivación ha sido "el principal caballo de Troya» (Accatino, 2009: 348) por medio del cual ha podido inmiscuirse un control ex post más o menos restringido de la prueba. Pero a la Corte no le ha faltado ocasión para exclamar como Laocoonte: ¡timeo Danaos et dona ferentes! Puede ocurrir que los elementos de juicio no contaminados por la prueba ilícita justifiquen inferencias probatorias en la misma línea señalada por esta prueba, pero con un menor grado de corroboración. Es decir, por sí solos (esto es, al margen de la prueba ilícita) aquellos elementos de juicio no consiguen afirmar el grado de probabilidad suficiente para dar por probada la hipótesis; grado que en este caso corresponde al estándar de prueba de "convicción" más allá de toda duda razonable.

El recurso de nulidad es ciego ante la situación recién retratada, pues la correcta aplicación del estándar de prueba escapa del ámbito de revisión permitido por este mecanismo ${ }^{24}$. Dada esta limitación, no puede confiarse a la motivación de la decisión judicial de los hechos la misión de servir de garantía definitiva frente a sentencias condenatorias fundadas en prueba ilícita y luego blindadas tras la férrea cortina de la "valoración negativa". Si, en cambio, se busca permanecer dentro del alcance del recurso de nulidad, alegando una infracción sustancial de garantías fundamentales, la Corte entenderá que falta la sustancialidad porque, al haberse valorado negativamente la prueba ilícita, el vicio carece de trascendencia, entendida -por influjo de la casación- como incidencia en lo dispositivo del fallo ${ }^{25}$. Así, pueden existir infracciones intrascendentes de derechos fundamentales que no acarrean la nulidad del juicio y de la sentencia. No es difícil que la Corte estime que ese sea el caso cuando el tribunal de juicio ha valorado negativamente la prueba ilícita: no obstante su ilicitud, ella no resulta trascendente porque el tribunal, según el mismo indica en la sentencia, no echó mano a ella para construir la fundamentación de la condena.

De este modo, la Sala Penal de la Corte Suprema de Chile ha abierto las puertas a la valoración de prueba ilícita y blindado el razonamiento que en ella se basa para condenar. Aunque puede decirse que se trata de un efecto contraproducente no bus-

$24 \mathrm{Al}$ respecto, Accatino, 20 io.

25 Sobre la exigencia de trascendencia, véase Del Río, 20 I 8. 
cado de manera intencional, en ocasiones la Corte ha llevado las cosas demasiado lejos. Incluso allí donde el tribunal de juicio ha valorado "positivamente" prueba ilícita, la Corte ha negado la nulidad porque, de sustraerse el elemento de juicio cuestionado (¡de acuerdo a un análisis ex post e hipotético!), el tribunal de juicio igualmente habría arribado a la decisión de condena ${ }^{26}$.

\section{CIERRE}

Los apartados precedentes representan un esfuerzo por desenmascarar lo que la Corte Suprema chilena hace (y no lo que dice que hace) cuando resuelve sobre un recurso de nulidad fundado en haberse dictado sentencia condenatoria sobre la base de prueba ilícita. Así, se ha empleado el caso chileno con la finalidad de mostrar que ciertos problemas acerca de la prueba ilícita son ignorados cuando no se atiende debidamente al diseño institucional del proceso penal.

La tarea anterior puede ser mejor emprendida utilizando las herramientas analíticas proporcionadas por la contemporánea teoría racional de la prueba. Así, por ejemplo, una cabal comprensión de las implicaciones de la bifurcación del tribunal puede alcanzarse a partir de la distinción entre reglas de exclusión intrínsecas y extrínsecas al razonamiento probatorio.

\section{BIBLIOGRAFÍA}

Accatino, D., 2010: «El modelo legal de justificación de los enunciados probatorios en las sentencias penales y su control a través del recurso de nulidad", en la misma (coord.), Formación y valoración de la prueba en el proceso penal. Santiago de Chile: Abeledo Perrot-Legal Publishing, 119-143.

— 2009: «Forma y sustancia en el razonamiento probatorio. El alcance del control sobre la valoración de la prueba a través del recurso de nulidad penal», en Revista de Derecho de la Pontificia Universidad Católica de Valparaíso, XXII: 347-362.

- 2006: «La fundamentación de la declaración de hechos probados en el nuevo proceso penal. Un diagnóstico", en Revista de Derecho (Valdivia), XIX (2): 9-26.

Aguilera Morales, M., 2008: «Regla de exclusión y Acusatorio», en Bachmaier, L. (coord.), Proceso penal y sistemas acusatorios. Madrid: Marcial Pons, 73-108.

Allen, R. et al., 2011: Criminal Procedure: Investigation and Right to Counsel (2nd ed.). New York: Wolters Kluwer.

ANDRÉs IBÁÑEZ, P., 2015: «El juez y la cuestión de hecho: formación de la convicción judicial», en su Tercero en discordia. Jurisdicción y Juez del Estado constitucional. Madrid: Editorial Trotta, 251-283.

26 Así, por ejemplo, en su sentencia de 5 de enero de 2014, rol no. 12.494-2013, sostuvo: «[A]un de no haberse cometido las infracciones [a las garantías del imputado] [los sentenciadores] igualmente habrían mantenido su veredicto condenatorio, privando entonces a lo alegado por el recurrente de influencia en lo dispositivo del fallo». Y en su sentencia de 14 de agosto de 2013, rol no. 4363-2013, resolvió: «[Aunque] en esta actuación [policial] pudiera existir una falta, lo cierto es que [el medio de prueba] constituye un antecedente más dentro de los varios otros que fueron analizados por los jueces del fondo". 
— 2003: «Sobre el valor de la inmediación (Una aproximación crítica)», en Jueces para la Democracia, 46: 57-66.

Araya Novoa, M., 2018: Recurso de nulidad penal y control racional de la prueba. De la epistemología a la praxis. Santiago de Chile: Librotecnia.

Armenta Deu, T., 2014: Estudios de Justicia Penal. Madrid: Marcial Pons.

- 2012: Sistemas procesales penales. La justicia penal en Europa y América. Madrid: Marcial Pons.

- 2011: La prueba ilícita (Un estudio comparado) (2a ed.). Madrid: Marcial Pons.

- 1998: «Principio acusatorio: realidad y utilización. Lo que es y lo que no», en Ius et Veritas, 16: 216-230.

Caenegem, R.C. van, 1993: Judges, Legislators and Professors. Chapters in European Legal History. Cambridge: Cambridge University Press.

Correa Robles, C., 2018a: «La buena fe del agente como excepción a la aplicación de la regla de exclusión - derecho estadounidense y derecho chileno -», en Latin American Legal Studies, 2: 25-50.

— 2018b: «Más allá de la regla de exclusión: prohibiciones probatorias en el Derecho chileno - con especial referencia al Derecho alemán -», en Política Criminal, 13 (25): Art. 4, 144-174.

Cortés-Monroy Fernández, J., 2018: «La "valoración negativa” como exclusión de la prueba ilícita en el juicio oral», en Revista Ius et Praxis, 24 (1): 661-692.

DAMAšKa, M., 1997: Evidence Law Adrift. New Haven: Yale University Press.

- 1986: The Faces of Justice and State Authority. A Comparative Approach to the Legal Process. New Haven: Yale University Press.

Del Río, C., 2018: «El principio de trascendencia en relación con el motivo de recurso de nulidad del artículo 373 letra a) del Código Procesal Penal chileno", en Política Criminal, 13 (25): Art. 9 , 322-349.

Duff, A., et al., 2007: The Trial on Trial, Vol. 3 Towards a Normative Theory of the Criminal Trial. Oxford: Hart Publishing.

Ferrer Beltrán, J., 2010: «La prueba es libertad, pero no tanto. Una teoría de la prueba cuasi-benthamiana", en Accatino, D. (coord.), Formación y valoración de la prueba en el proceso penal. Santiago de Chile: Abeledo Perrot-Legal Publishing, 1-19.

- 2007: La valoración racional de la prueba. Madrid: Marcial Pons.

Friedman, L., 1993: Crime and Punishment in American History. New York: Basic Books.

Friendiy, H., 1965: "The Bill of Rights as a Code of Criminal Procedure», en California Law Review, 53 (4): 929-956.

Hart, H.L.A., I982: "The Demystification of the Law», en sus Essays on Bentham. Studies in Jurisprudence and Political Theory. Oxford: Oxford University Press, 21-39.

Hernández Basualto, H., 2005: La Exclusión de la Prueba Ilícita en el Nuevo Proceso Penal Chileno. Santiago de Chile: Universidad Alberto Hurtado.

Horvitz Lennon, M. I., y López Masle, J., 2002: Derecho Procesal Penal Chileno, tomo II. Santiago de Chile: Editorial Jurídica de Chile.

Jackson, J. y Summers, S., 2012: The Internationalisation of Criminal Evidence. Cambridge: Cambridge University Press.

Kamisar, Y., 2006: «Mapp v. Ohio: The First Shot Fired in the Warren Court's Criminal Procedure "Revolution"», en Steiker, C. (ed.), Criminal Procedure Stories. New York: Foundation Press, 45-99.

Miranda Estrampes, M., 2013: Concepto de prueba ilícita y su tratamiento en el proceso penal. México: Ubijus Editorial.

— 2012: «¿En qué momento procesal puede acordarse la exclusión de una prueba obtenida de forma ilícita?», en Miranda, M., Cerda, R. y Hermosilla, F., Práctica de la prueba en el juicio oral. Su valoración y el estándar del "más allá de toda duda razonable". Santiago de Chile: Librotecnia.

— 2010: «La prueba ilícita: la regla de exclusión probatoria y sus excepciones», en Revista Catalana de Seguretat Pública, mayo de 2010: 131-151.

- 2003: «La regla de exclusión de la prueba ilícita: historia de su nacimiento y de su progresiva limitación", en Jueces para la Democracia, 47: 53-66.

Muffato, N., 2014: «Materiales para un análisis de los conceptos de relevancia probatoria y causal», en Papayannis, D. (coord.), Causalidad y atribución de responsabilidad. Madrid: Marcial Pons, 45-76. 
Nieva Fenoll, J., 2017: «Policía judicial y prueba ilícita. Regla de exclusión y efecto disuasorio: un error de base», en Diario La Ley, 9068: 1-35.

Rappaport, J., 2016: «An Insurance-Based Typology of Police Misconduct», en Coase-Sandor Working Paper Series in Law and Economics, 763: 369-405.

Roxin, C., 2000: Derecho procesal penal. Buenos Aires: Editores del Puerto.

— 1992: «Posición jurídica y tareas futuras del ministerio público», en VV.AA., El ministerio público en el proceso penal. Buenos Aires: Ad-Hoc, 37-57.

Schauer, F., 2006: «On the Supposed Jury-Dependence of Evidence Law», en University of Pennsylvania Law Review, 155 (1): 165-202.

TARuffo, M., 2011: La prueba de los hechos (4 ${ }^{\mathrm{a}}$ ed.). Madrid: Editorial Trotta.

- 2010: Simplemente la verdad. El juez y la construcción de los hechos. Madrid: Marcial Pons.

- 2008: La prueba. Madrid: Marcial Pons.

Tavolari, R., 2005: Instituciones del Nuevo Proceso Penal. Cuestiones y casos. Santiago de Chile: Editorial Jurídica de Chile.

Twining, W., 2006: "The Rationalist Tradition of Evidence Scholarship», en su Rethinking Evidence. Exploratory Essays. Cambridge: Cambridge University Press, 35-98.

- 1985: Theories of Evidence: Bentham and Wigmore. Stanford: Stanford University Press. 